\title{
Comprehensive Evaluation of Logistics Management Mode of Provincial Grid Companies Based on Analytic Hierarchy Process
}

\author{
Caiqing Zhang \\ Departmentof Economic Management \\ North China Electric Power University \\ Baoding, Hebei province
}

\author{
Minghan Zhang* \\ Department of Economic Management \\ North China Electric Power University \\ Baoding, Hebei province \\ 513344042@qq.com
}

\begin{abstract}
The effectiveness of grid logistics management mode has an direct effect on the efficiency of power grid as well as the safety of production, thus making it a necessity to build an evaluation system. This paper builds an evaluation index system of logistics management mode of provincial grid companies by combining domestic and international logistics management researches with present situation of grid logistics management mode. The weights will be determined by the AHP and Fuzzy Comprehensive Evaluation will be used to evaluate the results. In addition, the logistics management mode of a provincial grid company was also evaluated in this paper. The results obtained show that with some links to be improved, the provincial grid company's logistics management mode is more scientific and reasonable. Meanwhile, the results are able to provide some valuable references for grid companies for the optimization of their logistics management modes.
\end{abstract}

Keywords-Provincial Grid Corporation; Logistics management mode; AHP; Fuzzy comprehensive evaluation

\section{INTRODUCTION}

The power grid has important significances for the whole coordination and sustainable development of the service economy and society and it's an important foundation and guarantee for the development of modern economy and social progress [1]. There is a close supply and demand relationship between the logistics industry and the manufacturing industry, development [2]. For improving logistics management, effective comprehensive evaluation system is meaningful.

Li Xiaoke thinks that there are problems in the grid logistics management, for example, there isn't a perfect mechanism and the procurement method are being too single [3]. Wang Jinhu and others studied the construction of the provincial logistics company's modern logistics service system from aspects of warehousing and distribution management, standardization construction [4]. Gao Suying and others set up a new system for the Beijing-Tianjin-Hebei trade logistics industry to provide reference for optimizing the logistics system of the grid company [5]. Li Peidong and others have established a rating index system for the physical assets of the grid, which is of great significance for the establishment of indicators in this paper [6]. In recent years, many international power companies have begun to design long-term plans for the transition from material intensification to supply chain [7]. The current international power company's best practices has strategic procurement model [8], network logistics management and various logistics methods [9].

This article established an evaluation index system of the provincial grid company's logistics management mode and conduct a comprehensive evaluation of it.

\section{PROVINCIAL GRID COMPANY LOGISTICS MANAGEMENT MODE}

With the reform of the power system and the continuous development of power grid companies, the logistics management mode of the power grid company has undergone a transition from the management mode of the material section and the management mode of the material company to the current management mode of the logistics center.

\section{A. Provincial Power Grid Corporation Logistics \\ Management Organization Structure and Functions}

The grid company logistics management organization system is divided into company level and direct unit level. The establishment of the material department at the company level is responsible for the material planning, procurement, warehousing, quality supervision, supplier relations, disposal of waste materials, etc., as well as the company's headquarters to carry out logistics management work. Material company changed to supply chain management center, it is responsible for provincial company's material demand plans, tender procurement agency services, warehousing and distribution, material settlement, inventory and emergency materials management. A logistics management center would be established at the level of the directly-affiliated units and be responsible for the reporting of materials demand plans, distribution and warehousing of local(city)companies, the collaboration work in unified distribution warehousing service with contract signed by the supply chain management center. 
B. The main processes of provincial power grid company's logistics management mode

At present, the logistics company's logistics center management is an intensive closed-loop management mode, in accordance with the process of material planning, procurement, warehousing and distribution, quality supervision, supplier relationship management, etc., The specific process is shown in Figure 1.

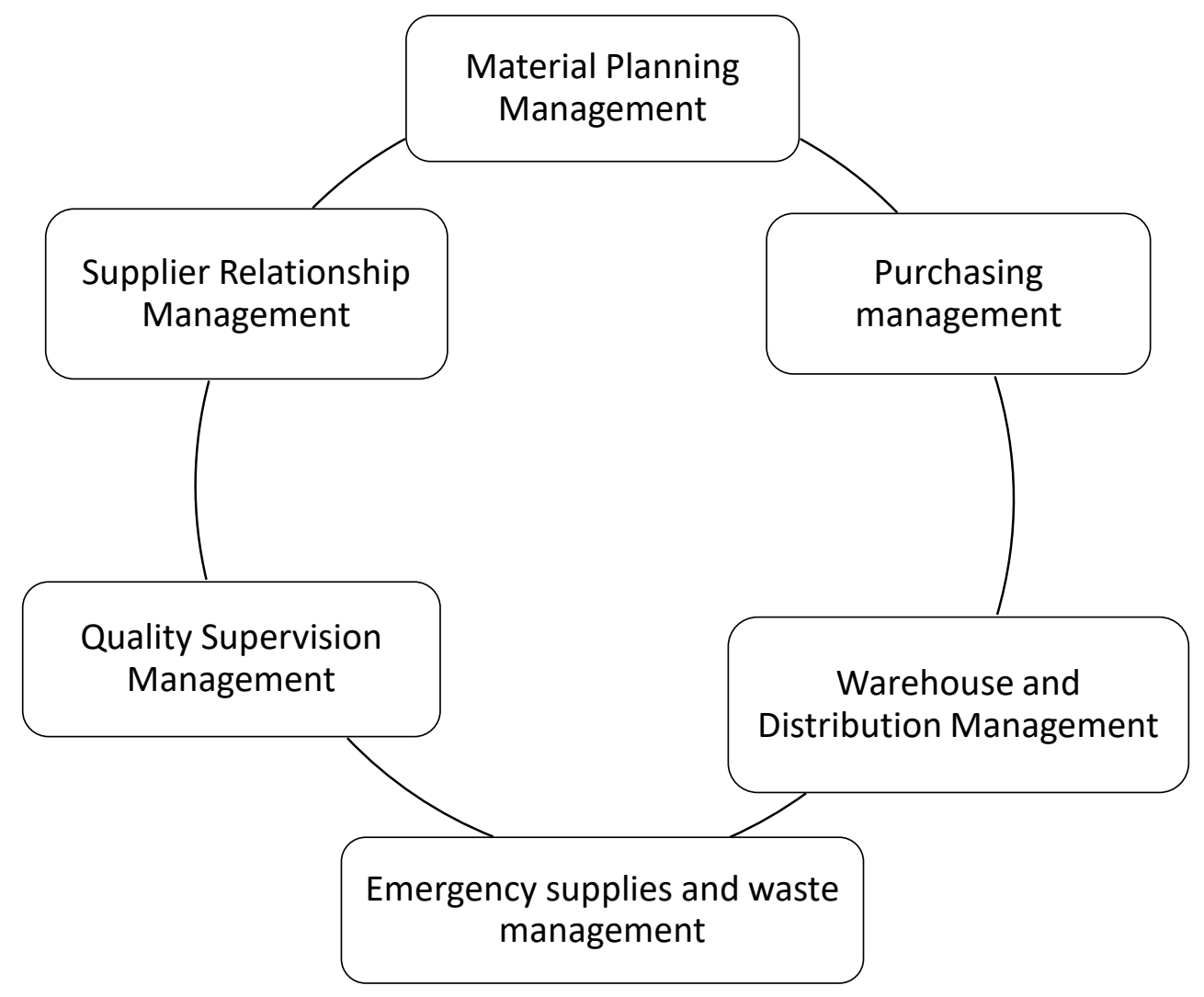

Fig. 1 Processes of provincial grid company logistics management mode

III. CONSTRUCTION OF EVALUATION INDEX SYSTEM FOR LOGISTICS MANAGEMENT MODE OF PROVINCIAL POWER GRID COMPANIES

\section{A. Principles of Evaluation Index System Construction}

The design of indicator dimensions and the determination of indicators in the evaluation index system are the important basis for determining whether the research ideas of this paper can be carried out smoothly [10]. And the process of choosing indicators should follow the main principles of science, comprehensiveness, feasibility, etc.

\section{B. Evaluation Model of Logistics Management Mode of Provincial Power Grid Company}

Through the analysis and arrangement of the grid company's logistics management model, the analysis focuses on six aspects, which include planning procurement, warehousing and distribution, supplier relations, supervision and management, and basic management. In addition, the evaluation index system of the provincial grid company's logistics management model is shown in Table 1. 


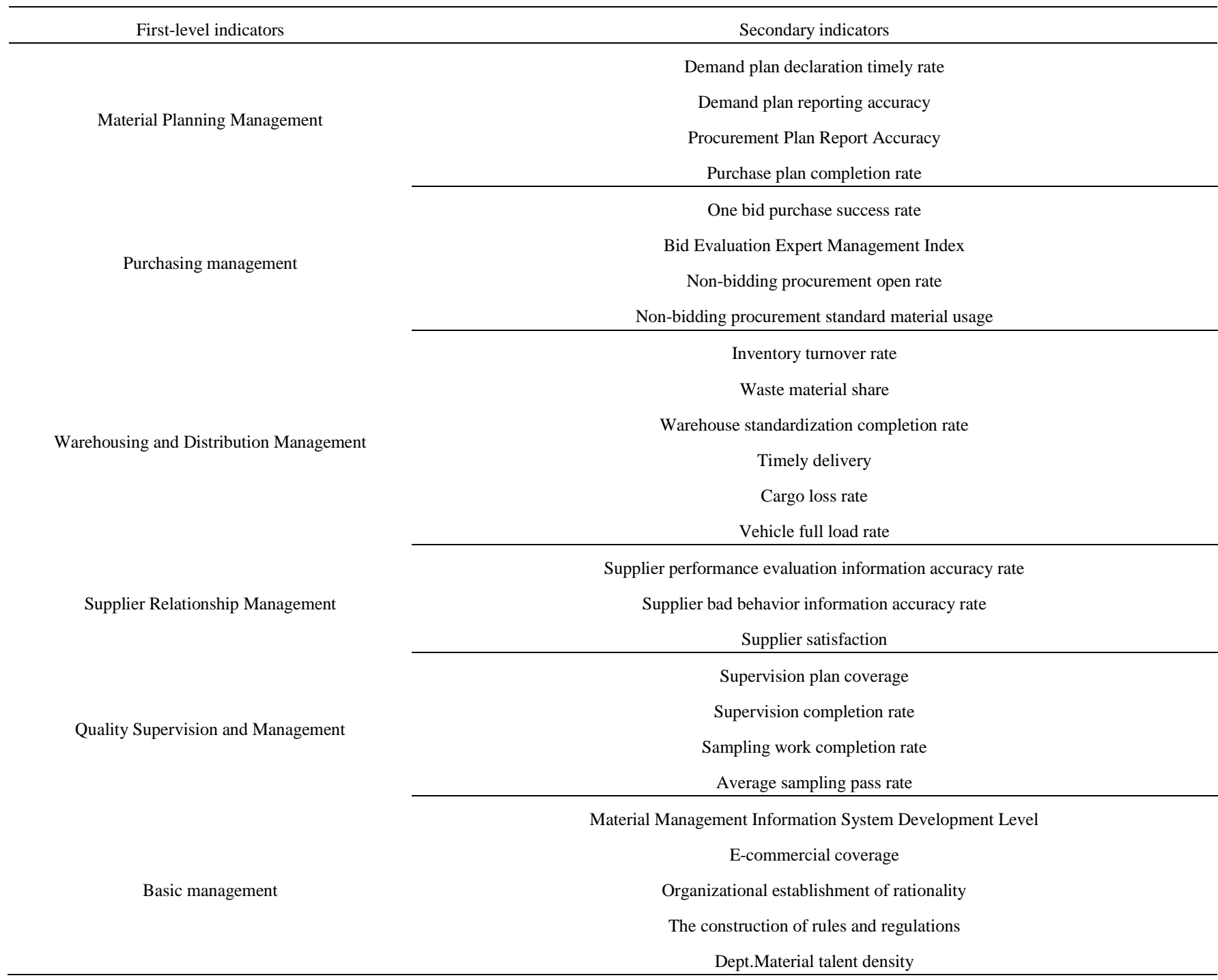

\section{EVAluation of Logistics Management Mode of PROVINCIAL GRID CORPORATION}

This paper conducts a comprehensive evaluation of a provincial grid company.

A. Determine the evaluation set and weights

\section{1) Determine the evaluation set}

The evaluation set should be: $V=\left\{V_{1}, V_{2}, V_{3}, V_{4}\right\}=\{$ excellent, good, moderate, poor $\}$

For the sake of the following scores, it is also possible to use the specific number 4,3,2,1 to express four levels.

2) Determine the evaluation weights

The weight is a corresponding weight assigned to each indicator U, generally,satisfy: anda fuzzy set A (weight set) consisting of $a_{i}$ by U.This paper selects the analytic hierarchy process to determine the weights (all have completed the consistency test).The weights are shown in Table 2. 
TABLE II ALL INDICATORS’ WEIGHTS

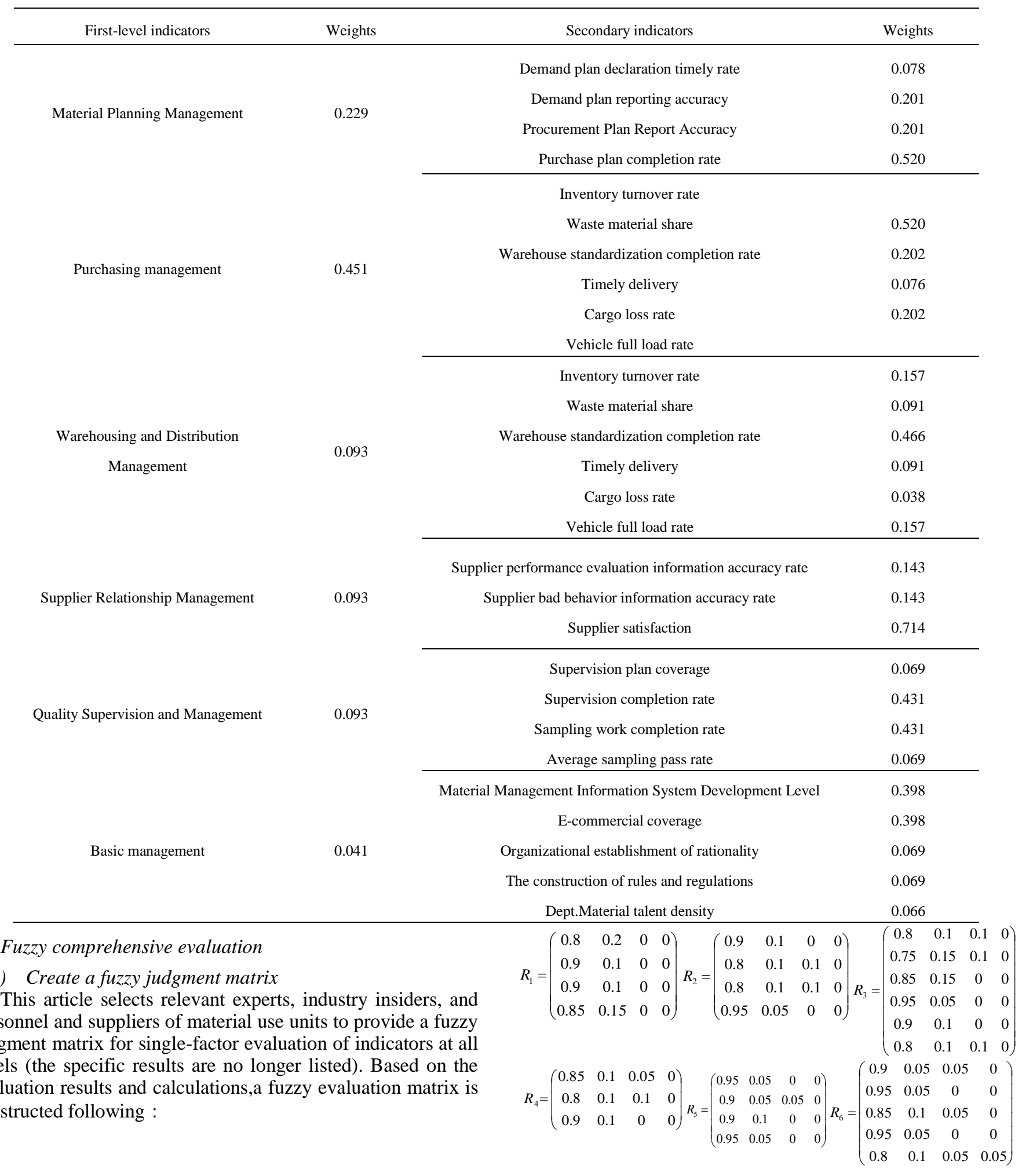


2) Fuzzy Comprehensive Evaluation of the First Level

Based on the weights and fuzzy matrix obtained above, we get:

$$
\begin{gathered}
B_{1}=A_{1} \circ R_{1}=\left(\begin{array}{llll}
0.866 & 0.134 & 0 & 0
\end{array}\right) \\
B_{2}=A_{2} \circ R_{2}=\left(\begin{array}{llll}
0.882 & 0.090 & 0.028 & 0
\end{array}\right) \\
B_{3}=A_{3} \circ R_{3}=\left(\begin{array}{llll}
0.836 & 0.123 & 0.041 & 0
\end{array}\right) \\
B_{4}=A_{4} \circ R_{4}=\left(\begin{array}{llll}
0.879 & 0.1 & 0.021 & 0
\end{array}\right) \\
B_{5}=A_{5} \circ R_{5}=\left(\begin{array}{llll}
0.907 & 0.072 & 0.021 & 0
\end{array}\right) \\
B_{6}=A_{6} \circ R_{6}=\left(\begin{array}{llll}
0.913 & 0.057 & 0.027 & 0.003
\end{array}\right)
\end{gathered}
$$

3) Fuzzy Comprehensive Evaluation of the Second Level

Used the above-mentioned first-order evaluation vector as an upper-level index evaluation matrix,the second level fuzzy comprehensive evaluation:

$$
B=A \circ R=\left(\begin{array}{llll}
0.877 & 0.101 & 0.021 & 0.001
\end{array}\right)
$$

In order to see more intuitively about the level of the provincial power grid company's logistics management model is, we combine the evaluation and evaluation results of the comments above. Using formulas to calculate the composite score:

$$
\begin{gathered}
M=3.854, \quad M_{1}=3.866, \quad M_{2}=3.854, \quad M_{3}=3.795, \\
M_{4}=3.858, \quad M_{5}=3.866, \quad M_{6}=3.88
\end{gathered}
$$

4) Comments and suggestions

Overall, the final score of a provincial power grid company's logistics management mode is 3.854 , which is a small gap from the full score of 4 points, but it isn't perfect. The score of Warehousing and Distribution Management is 3.795 , it is weaker than others, can reducing the occupation of waste materials and increasing the turnover rate.

\section{CONCLUSION}

Through the comprehensive evaluation of a provincial power grid company's logistics management mode, we found that the entire mode has gradually improved, and the institutional setup and system construction are also reasonable, the efficiency of work has also been relatively high. However, as can be seen from the results, various tasks are not perfect, and there are also some aspects can be improved.

\section{REFERENCES}

[1] Liu Zhenya. “China Power and Energy”.Beijing: China Electric Power Press. 2012,pp. 151.(In Chinese)

[2] TIAN Xue, SI Weipeng, YANG Jianglong."Relationship between network embeddedness and service innovation performance of logistics enterprise:Based on dynamic capability."Technical Economics, 2015,vol.34(1),pp. 62-68. (In Chinese)

[3] LI Xiaoke. "Research on intensive management of power supply enterprises,"China Logistics and Procurement,2014,vol.23,pp. 70-71. (In Chinese)

[4] WANG Jinhu, GUO Wei. "Provincial grid corporation modern logistics service system construction," Business Management,2016,vol.2,pp. 464465. (In Chinese)

[5] GAO Suying, GAO Ying, ZHANG Ye. "Construction of new system of trade logistics industry in Beijing-Tianjin-Hebei region based on inclusive growth,’'Technical Economics, 2017,vol.36(8),pp. 109-117. (In Chinese)

[6] LI Peidong, HONG Menglin, SHANG Sang. "Evaluation index system on grid physical assets,"Power construction, 2014,vol.35(8),pp. 145-150. (In Chinese)

[7] Ma Shihua. "Supply Chain Management,"Beijing.Machinery Industry Press,2000,pp. 55-77. (In Chinese)

[8] James Stock Douglas Lambert. "Strategy logistics management,"USA:Mc Graw-Hill,2006,pp. 126.

[9] Zhang Jingwei. "Research on Material Intensive Management of $\mathrm{H}$ Power Company,"North China Electric Power University,2011. (In Chinese)

[10] Perrault W D,RUSS, "Physical distribution service:a neglected aspect of business topics," Marketing management,2010,pp. 125-127. 